\title{
THE LOCAL EXUDATIVE CELLULAR RESPONSE IN LEUKEMIA*
}

\author{
By PASQUALE E. PERILLIE† AND STUART C. FINCH
}

(From the Department of Internal Medicine, School of Medicine, Yale University, and the Grace-New Haven Community Hospital, New Haven, Conn.)

(Submitted for publication March 22, 1960 ; accepted April 22, 1960)

The present study was undertaken to examine the local exudative cellular response in patients with leukemia and to determine whether alterations in the pattern of response might further explain their increased susceptibility to infection. Portions of the complex process of host resistance have been shown to be abnormal in leukemia (1-4). Some studies have demonstrated reduced phagocytic activity of the neutrophilic granulocytes in chronic granulocytic leukemia $(3,4)$, but this opinion is not universally shared (5). Although natural antibody levels appear to be maintained in leukemia (6), impaired de novo antibody synthesis has been demonstrated in chronic lymphocytic leukemia (1, 2 ). Despite the fundamental role of the inflammatory reaction in determining the body's resistance to bacterial invasion, the characteristics of this important defense mechanism have received little attention in leukemia.

\section{MATERIALS AND METHODS}

A group of 26 patients with various types of acute and chronic leukemia and 10 hematologically normal subjects were included in this study. The normal subjects were

* This investigation was supported by a research grant, H-1577 (C5) National Heart Institute, Public Health Service, Bethesda, Md. This paper was presented in part at the Eastern Section of the American Federation for Clinical Research, December 10, 1959.

† United States Public Health Research Fellow. adults admitted to the hospital with a variety of disorders, none of which would be expected to interfere with the local inflammatory response.

Of the 26 patients with leukemia, 20 were male and 6 were female. Their ages ranged from 18 to 74 . Most of the chronic leukemia patients were in adequate hematological remission and were receiving maintenance chemotherapy, while most of the acute leukemia patients were in an active phase of their disease (Table I).

The method employed was a modification of the glass coverslip technique developed by Rebuck and Crowley and described in detail elsewhere (7). The skin over a small area of the volar surface of the forearm was scraped with a sterile scalpel until the papillary layer of the corium was exposed. The lesion then was covered with a sterile glass coverslip which in turn was surmounted by a sterile cardboard square and 2 inch surgical tape. The cells responding to the combined stimulation of the surgical abrasion and glass surface adhered to the undersurface of the coverslip. The coverslips were removed at timed intervals, quickly air-dried, stained with WrightGiemsa and mounted on glass slides.

The slides were then examined microscopically. Each preparation was carefully examined with a low power scanning lens and its relative cellularity determined. At each stage of the local exudative cellular reaction the normal responses were graded as showing maximum cellularity $(4+)$. Each leukemic preparation was then graded 0 to $4+$ in comparison to the normal response at a comparable stage of the inflammatory cycle. The morphology and maturity of the local cellular exudates were determined under an oil immersion lens. Serial coverslip preparations were obtained at hourly intervals from each lesion for the first 12 to 14 hours and at 22 to 24 hours after the initiation of the inflammatory

TABLE I

Clinical description of patients studied

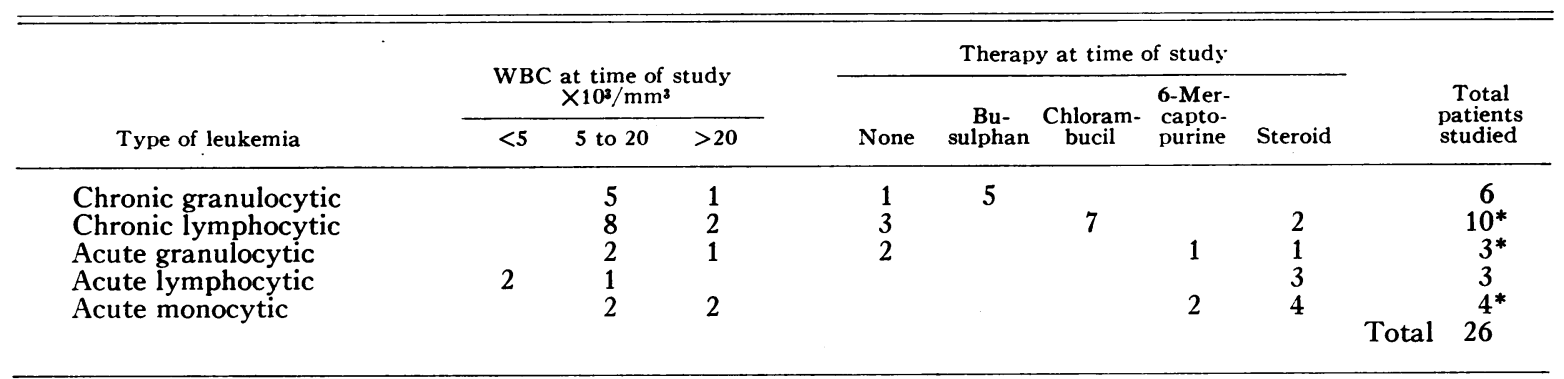

* Some patients were receiving combined therapy. 

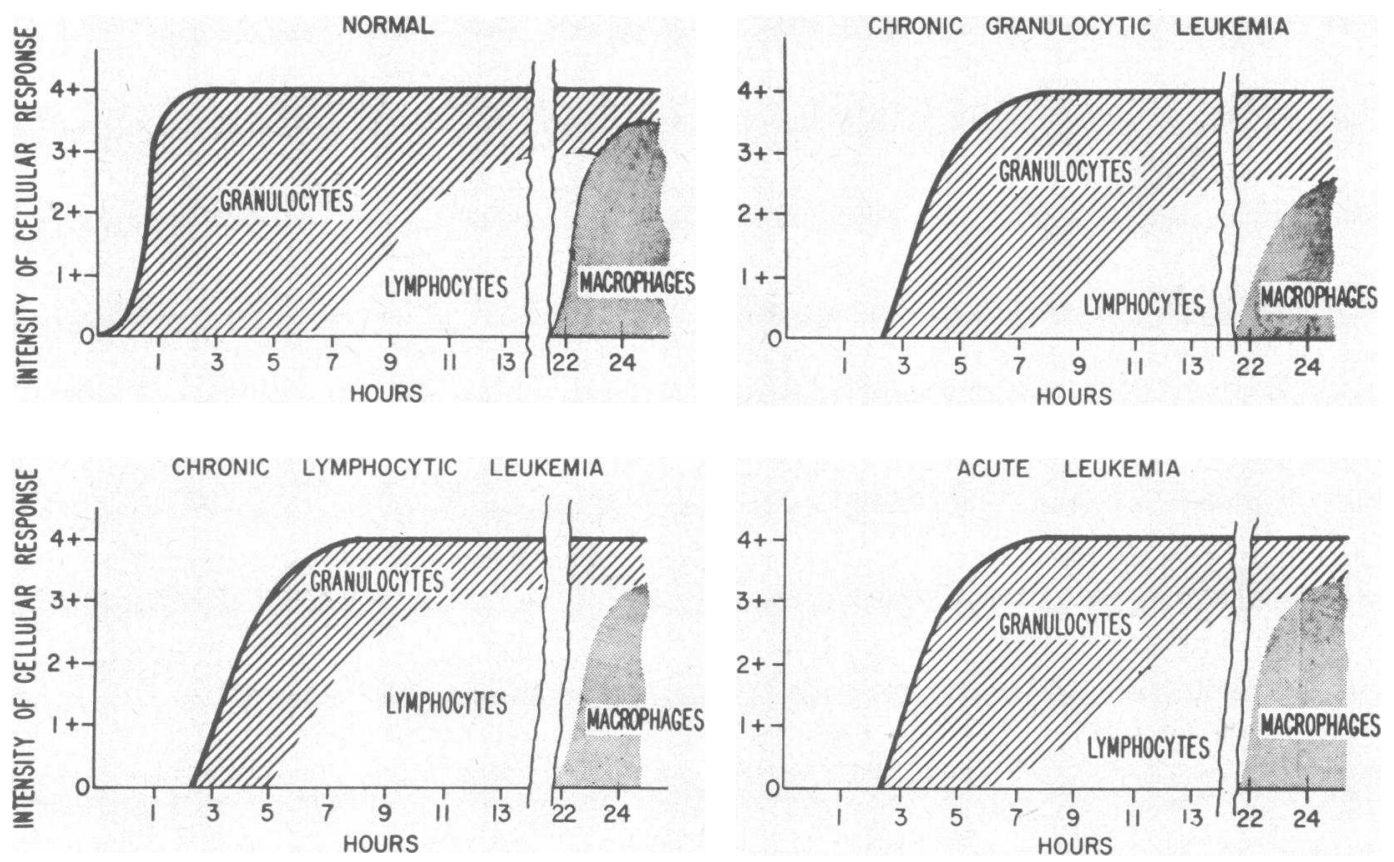

Fig. 1. Graphic Representation of the local Cellular response in NORMal subjects and in patients with LEUKEmIA. The heavy line represents the intensity of the local cellular responses graded 0 to $4+$ (see text). The area below the heavy line is partitioned to show the time of initial appearance and relative participation of the three main types of responding cells during the 24 hour period studied.

response. Two lesions were studied on the forearm of each patient and control subject.

\section{RESULTS}

Local cellular response in normal subjects (Figure 1). In general our findings in the normal subjects agreed with the earlier reports of Rebuck and Crowley (7). At about 1 to 1.5 hours following injury a heavy concentration of mature neutrophilic granulocytes was noted on the coverslip. This phase persisted for the first 6 to 8 hours of the inflammatory cycle. During this period there was minor participation by tissue histiocytes, eosinophils and lymphocytes. At the eighth to tenth hour of the cycle large, mature lymphocytes began appearing in increasing numbers and by the fourteenth hour they made up about 50 per cent of the local cellular exudate. From this point in the inflammatory cycle an increasing number of large, sessile macrophages was noted so that by the twenty-second to twenty-fourth hour they comprised over 80 per cent of the cells present. Rebuck and Crowley have shown these cells to be derived from the lymphocytes present earlier and from tissue histiocytes (7).
Local cellular response in leukemic patients (Figure 1). The local cellular response in patients with leukemia differed in several ways from the normal. In all patients studied the initial neutrophilic granulocyte response was delayed in its onset, beginning usually 3 to 3.5 hours following injury. In comparison with the normal this initial response was sparse, and maximum cellularity developed more slowly (Figure 2).

In most of the patients with chronic granulocytic leukemia, granulocytes persisted in significant numbers throughout the 24 hour period. Of additional interest was the participation of significant numbers of basophils in the local response of these patients (Figure 3 ).

In chronic lymphocytic leukemia increasing numbers of mature lymphocytes began appearing at the fifth to seventh hour, whereas in the normal subjects this phenomenon did not begin until the eighth to tenth hour of the local cellular response (Figure 4).

Except for the altered initial granulocyte response the patients with acute leukemia demonstrated no characteristic cellular patterns.

In general the local exudative responses were 


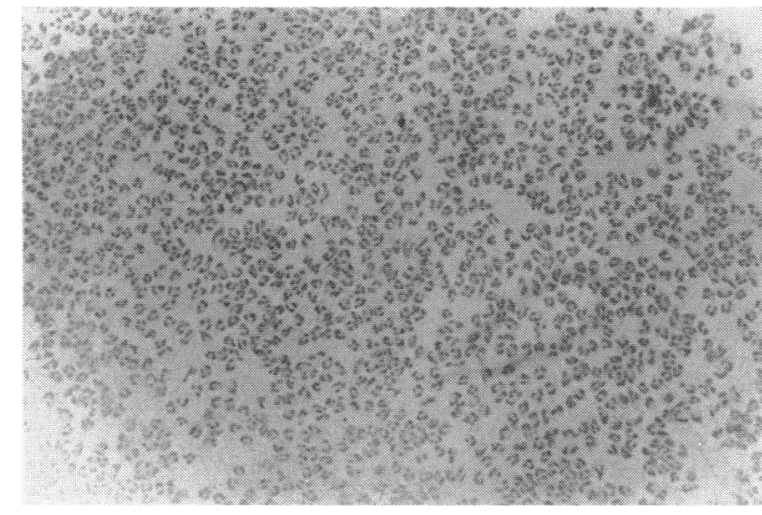

A

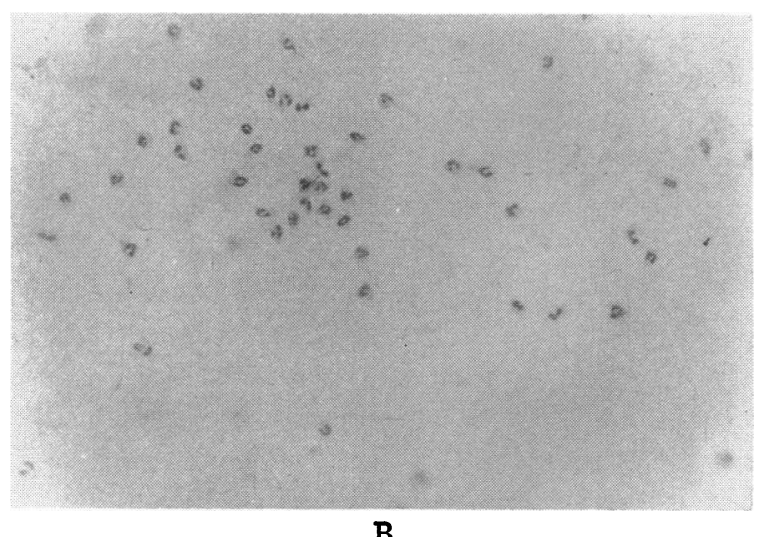

B

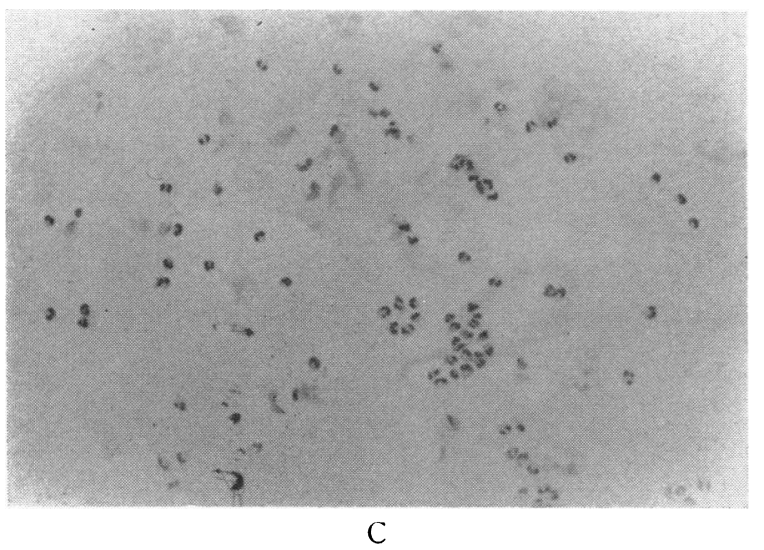

Fig. 2. ForEARM COVERSLIP PREPARATIONS AT THE THIRD HOUR OF THE LOCAL INFLAMMATORY CYCLE SHOWING THE MORPHOLOGY AND INTENSITY OF THE INFLAMMATORY RESPONSE. A) Normal $(4+)$; B) chronic granulocytic leukemia $(1+) ; C)$ acute lymphoblastic leukemia $(1+)(\times 1,200)$

made up primarily of morphologically mature cells regardless of the morphology and cellularity of the peripheral blood or bone marrow. This was most strikingly demonstrated in the patients with acute leukemia (Figure 5). In only one patient in this latter group were a few nucleolated cells of histiocytic type seen in the late stages of the local exudative response. Two patients with acute subleukemic leukemia showed no cellular response in the 24 hour period studied. The characteristics of the inflammatory responses observed in these patients had no relationship to either the type of therapy or degree of hematological remission. Even those patients with chronic leukemia whose total leukocyte counts were within the normal range showed the delayed granulocyte response in the local inflammatory reaction. Neither age nor sex appeared to have a significant effect on the responses described.

\section{DISCLSSION}

The morphologic characteristics of the inflammatory exudate were easily reproducible. In both groups the time sequence for the appearance of particular cell types showed little variation from patient to patient. The injury produced by the abrasion and the continued application of the coverslips was sufficient to reproduce the complete inflammatory cycle described by Rebuck and Crowley using specific nonpyrogenic bacterial substances (7). The leukocyte preparations obtained were well preserved permitting accurate identification of cellular morphology and maturity. Despite limitations in quantitation, the decreased intensity of the early granulocytic response in the leukemic patient was so obvious that it is believed to be significant.

The results of these experiments demonstrate that the early exudative cellular response of inflammation in various types of leukemia is both delayed and diminished in comparison to the normal. Earlier studies of the local inflammatory reaction have shown the first few hours of this response to be the crucial period which determines the success or failure of microbial invasion (8). The neutrophilic granulocyte is considered the cell of major importance during this phase of the body's defense and its prompt arrival in adequate numbers at the site of injury constitutes the first line of defense against such invasion. The delayed and diminished granulocyte response demonstrated in our patients may provide a more adequate explanation for the susceptibility of leukemic patients to infection. It is interesting to note that similar 

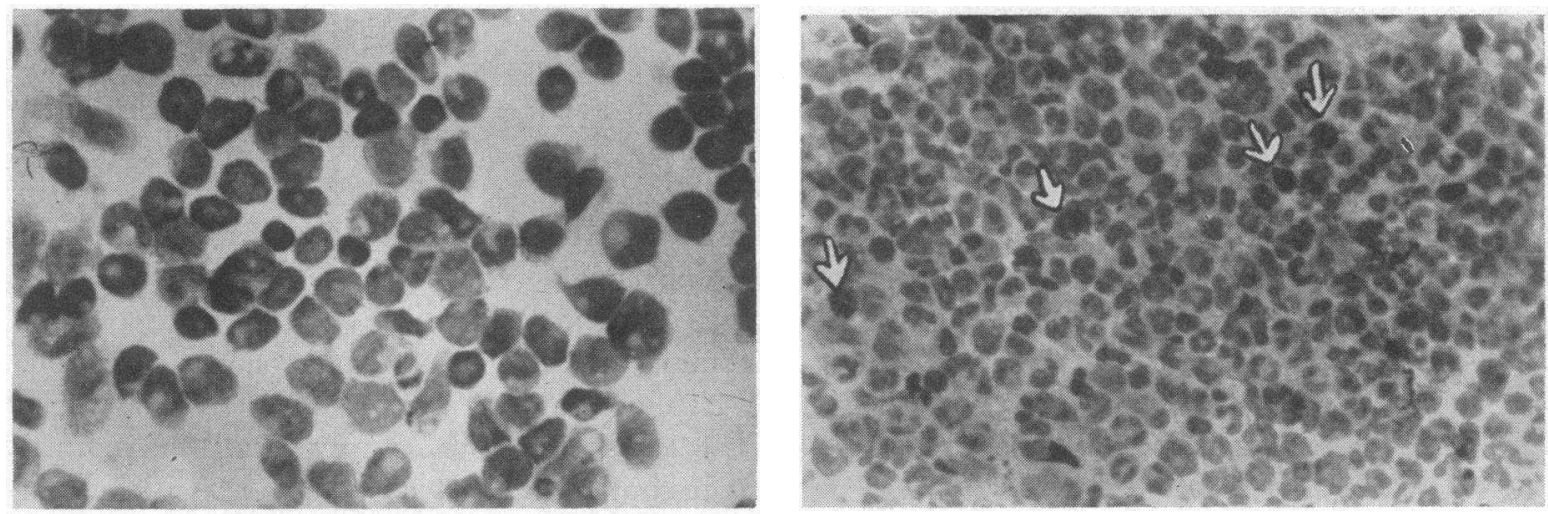

Fig. 3. LOCAL INFLAMMATORY REACTION IN CHRONIC GRANULOCYTIC LEUKEMIA (RIGHT) $(\times 1,500)$ AND IN NORMAL SUbJeCtS (LEFT) $(\times 1,600)$ AT THE TWENTY-SECOND hour OF INFLAMmation. Several of the numerous basophils present are marked (arrows).

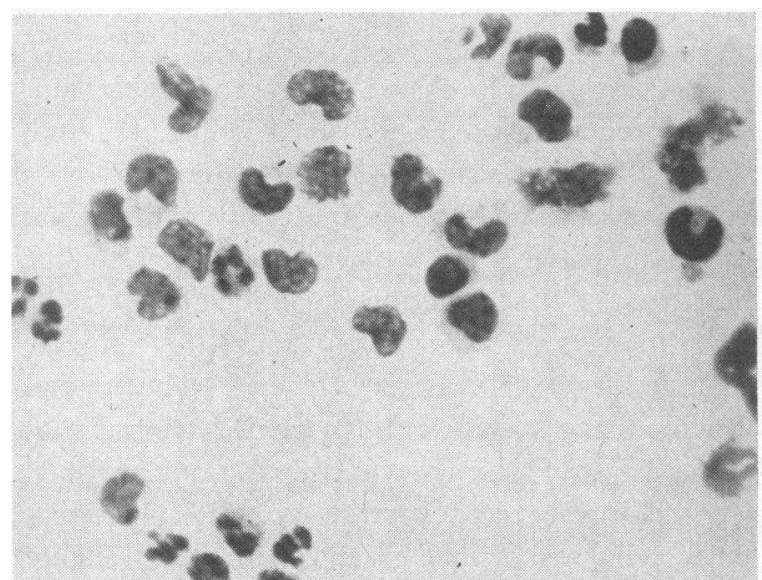

Fig. 4. A 5.5 hour PREParation in CHRONIC LYMPHOCYTIC LEUKEMIA SHOWING THE PRESENCE OF SIGNIFICANT NUMBERS OF LYMPHOCYTES. These cells are frequently fixed in ameboid motion accounting for their irregular cellular outlines and the exaggerated indentations of the nuclei $(\times 1,600)$.

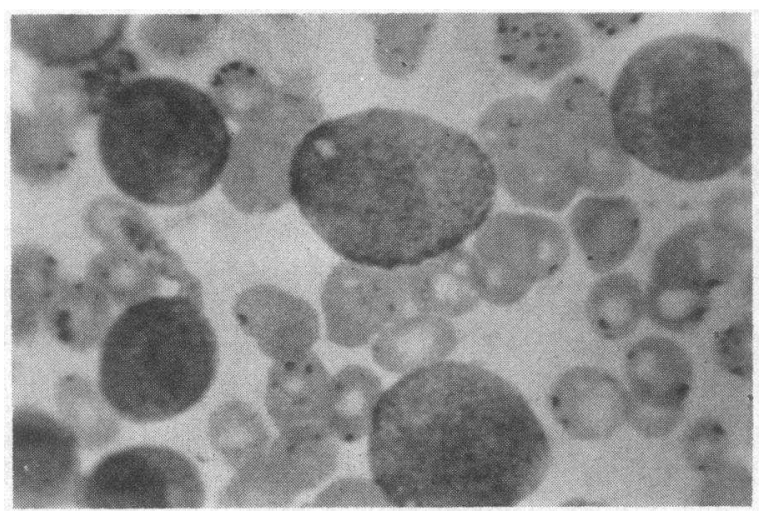

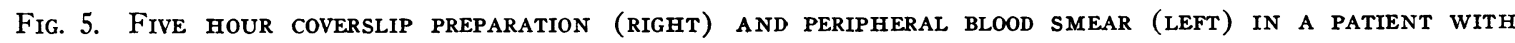
ACUTE MONOCYTIC LEUKEMIA CONTRASTING THE MATURITY OF THE LOCAL CELLULAR RESPONSE TO THE IMMATURITY OF THE PERIPHERAL BLOOD $(\times 2,000)$.

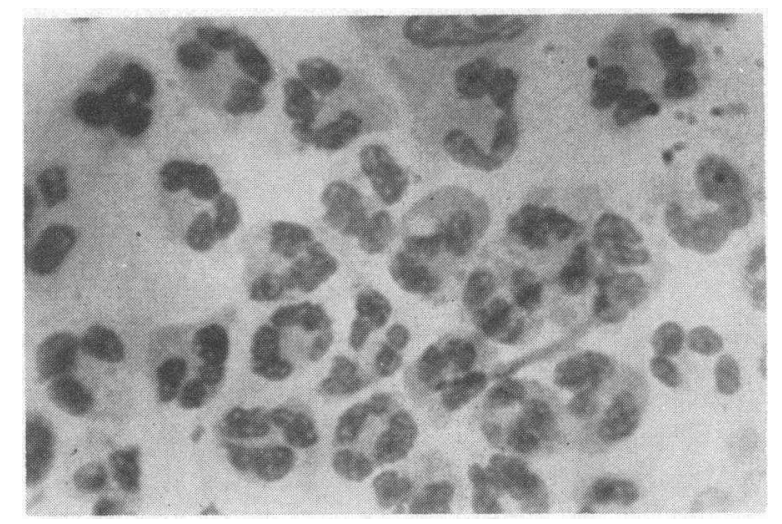

defects in the local defense reaction have been demonstrated in diabetic rabbits (9). These results also were interpreted as indicating increased susceptibility to infection.

Dionisi (10) and Bickhardt (11) have stated that patients with leukemia respond to inflammation with immature leukemic cells. Except for the atypical and somewhat immature appearing cells which were noted late in the response of one of our patients with acute leukemia, we found, as Jaffe did, that the patients with leukemia responded to inflammation with morphologically mature cells (12).

The appearance of heavy concentrations of mature polymorphonuclear leukocytes on the coverslip preparations of the patients with chronic lymphocytic leukemia was in striking contrast to the differential leukocyte counts of the peripheral blood. In spite of the preponderance of circulating 
lymphocytes in these patients, the number of circulating mature granulocytes usually was within normal limits. It is well known that purulent exudates in patients with chronic lymphocytic leukemia consist primarily of polymorphonuclear leukocytes.

Others have shown that the degree of participation of specific mature cells in local inflammatory sites is in general related to their numbers in the circulating blood (13). This relationship was demonstrated by the preponderance of neutrophilic and basophilic granulocytes throughout the 24 hour period in the patients with chronic granulocytic leukemia and the early appearance of lymphocytes in most of the patients with chronic lymphocytic leukemia.

Jaffe has stated that some myeloid tissue capable of maturation must be present in leukemic patients if the cellular response to inflammation is to occur (12). The failure of two of our patients with acute subleukemic leukemia to show any local exudative cellular response to injury during the period studied could be explained in this manner. Both had peripheral white cell counts below 1,000 per $\mathrm{cu} \mathrm{ml}$ consisting almost entirely of blast cells. In addition, repeated attempts at marrow aspirations were unsuccessful and trephine specimens demonstrated hypocellular, blastic marrows.

We have found the method used in this study a reliable, safe and simple one which lends itself to clinical applications. It may be useful in evaluating the exudative cellular aspects of the local inflammatory response in other disease states.

\section{SUMMARY AND CONCLUSIONS}

In leukemia, the initial granulocyte response to inflammation is both delayed and diminished. This feature of the exudative cellular response probably plays a major role in the susceptibility of these patients to infection. In general, the local exudative cellular response in leukemia is comprised of morphologically mature cells. The tech- nique employed should prove valuable for evaluating the local inflammatory response in other disease states.

\section{REFERENCES}

1. Howell, K. M. The failure of antibody formation in leukemia. Arch. intern. Med. 1920, 26, 706.

2. Larson, D. L., and Tomlinson, L. J. Quantitative antibody studies in man. III. Antibody response in leukemia and other malignant lymphomata. J. clin. Invest. 1953, 32, 317.

3. Jersild, M. Phagocytic activities of various types of leukocytes. Acta med. scand. 1948, 131, suppl. 213, 238.

4. Braude, A. I., Feltes, J., and Brooks, M. Differences between the activities of mature granulocytes in leukemia and normal blood. J. clin. Invest. 1954, 33, 1036.

5. Strumia, M. M., and Boerner, F. Phagocytic activity of circulating cells in the various types of leukemia. Amer. J. Path. 1937, 13, 335.

6. Brody, J. I., and Finch, S. C. Candida reacting antibody in the serum of patients with lymphomas and related disorders. Blood $1960, \mathrm{XV}$. In press.

7. Rebuck, J. W., and Crowley, J. H. A method of studying leukocyte functions in vivo. Ann. N. Y. Acad. Sci. 1955, 59, 757.

8. Miles, A. A., Miles, E. M., and Burke, J. The value and duration of defense reactions of the skin to the primary lodgement of bacteria. Brit. J. exp. Path. 1957, 38, 79.

9. Sheldon, W. H., and Bauer, H. The development of the acute inflammatory response to experimental cutaneous mucormycosis in normal and diabetic rabbits. J. exp. Med. 1959, 110, 845.

10. Dionisi, A. On the intralveolar exudative elements in leukemia complicated by pneumonia. Folia haemat. (Lpz.) 1909, 7, 368.

11. Bickhardt, $K$. Uber morphologische Befunde bei Entzündungsvorgängen in Fällen von Leukämie. Folia haemat. (Lpz.) 1926, 32, 83.

12. Jaffe, R. H. Morphology of the inflammatory defense reactions in leukemia. Arch. Path. (Chicago) 1932, 14, 177.

13. Frerichs, J. B. The influence of a monocytosis of the peripheral blood stream upon the cellular character of an acute inflammation. Johns Hopk. Hosp. Bull. 1944, 74, 49. 